\title{
Multispecies fisheries management in the Mediterranean Sea: application of the Fcube
} methodology

Maravelias, C.D.; Damalas, D.; Ulrich, Clara; Katsanevakis, S.; Hoff, A.

Published in:

Fisheries Management and Ecology

Link to article, DOI:

10.1111/j.1365-2400.2011.00801.x

Publication date:

2012

Link back to DTU Orbit

Citation (APA):

Maravelias, C. D., Damalas, D., Ulrich, C., Katsanevakis, S., \& Hoff, A. (2012). Multispecies fisheries management in the Mediterranean Sea: application of the Fcube methodology. Fisheries Management and Ecology, 19(3), 189-199. https://doi.org/10.1111/j.1365-2400.2011.00801.x

\section{General rights}

Copyright and moral rights for the publications made accessible in the public portal are retained by the authors and/or other copyright owners and it is a condition of accessing publications that users recognise and abide by the legal requirements associated with these rights.

- Users may download and print one copy of any publication from the public portal for the purpose of private study or research.

- You may not further distribute the material or use it for any profit-making activity or commercial gain

- You may freely distribute the URL identifying the publication in the public portal 
Fisheries Management and Ecology Volume 19, Issue 3, pages 189-199, June 2012 http://dx.doi.org/10.1111/j.1365-2400.2011.00801.x @ 1999-2013 John Wiley \& Sons, Inc.

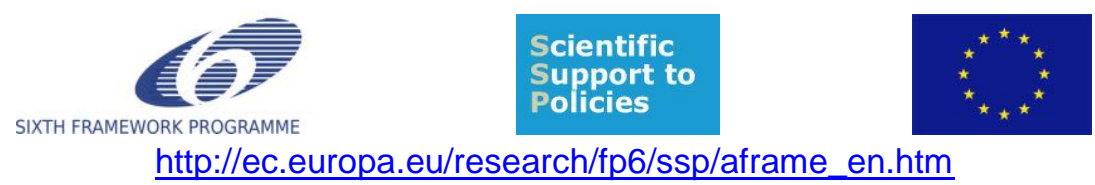

\title{
Multispecies fisheries management in the Mediterranean Sea: application of the Fcube methodology
}

\author{
Christos D. Maravelias ${ }^{1}$, Dimitrios Damalas ${ }^{1}$, Clara Ulrich ${ }^{2}$, \\ Stelios Katsanevakis ${ }^{1} \&$ Ayoe Hoff ${ }^{3}$
}

\footnotetext{
${ }^{1}$ Hellenic Centre for Marine Research, 46.7 km Athens-Sounio, 19013 Anavyssos, Attica, Greece. tel: +30 210 9856703; fax: +30 210 9811713; e-mail: cmaravel@ath.hcmr.gr

${ }^{2}$ DTU Aqua, Charlottenlund Castle, 2920 Charlottenlund, Denmark. Email: clu@aqua.dtu.dk

${ }^{3}$ University of Copenhagen, Institute of Food and Resource Economics, Rolighedsvej 25, 1958

Frederiksberg C, Denmark. Email: ah@foi.dk
}

\begin{abstract}
The ecosystem approach (EA) advocates that advice should be given based on a holistic management of the entire marine ecosystem and all involved fisheries and fleets. Recent developments have advanced to multi-species, multi-fisheries advice, rather than on a single species/fleet/area stock basis, bridging the gap between existing single species approaches and the needs of the EA. The 'Fcube' method estimates potential levels of effort by fleet in mixed fisheries situations to achieve specific targets of fishing mortality. Data on effort, landings and socioeconomic parameters were used for coastal and trawl fisheries in the Aegean Sea. Results pointed out the strengths and weaknesses of alternative management strategies from both a biological and socioeconomic perspective. Fcube revealed the importance of effort control in the coastal fisheries that are still managed with no effort restrictions. The present findings, although preliminary, revealed that stringent cuts to effort and catch levels are required if the EA management goals are to be met. The Fcube methodology, initially developed for mixed fisheries advice in northern European waters that are managed with TACs, it also proved promising in providing advice to no-TAC fisheries.
\end{abstract}

Keywords: fleet, effort, socioeconomics, ecosystem approach, advice, demersal, TAC, landings

*Corresponding author: tel: +30 210 9856703; e-mail: cmaravel@ath.hcmr.gr

Article first published online: 21 Oct 2011

Please note that this is an author-produced PostPrint of the final peer-review corrected article accepted for publication. The definitive publisher-authenticated version can be accesses here:

http://dx.doi.org/10.1111/j.1365-2400.2011.00801.x @ 1999-2013 John Wiley \& Sons, Inc. 
1 Multispecies fisheries management in the Mediterranean Sea: application of the Fcube

2 methodology.

3

4

119811713 ; e-mail: cmaravel@ath.hcmr.gr

12 Dimitrios Damalas, Hellenic Centre for Marine Research, 46.7 km Athens-Sounio,

1319013 Anavyssos, Attica, Greece. Email: shark@ath.hcmr.gr

14 Clara Ulrich, DTU Aqua, Charlottenlund Castle, 2920 Charlottenlund, Denmark.

15 Email: clu@aqua.dtu.dk

16 Stelios Katsanevakis: Hellenic Centre for Marine Research, 46.7 km Athens-Sounio,

1719013 Anavyssos, Attica, Greece. Email: skatsan@ath.hcmr.gr

18 Ayoe Hoff, University of Copenhagen, Institute of Food and Resource Economics,

19 Rolighedsvej 25, 1958 Frederiksberg C, Denmark. Email: ah@ @oi.dk 9811713; e-mail: cmaravel@ath.hcmr.gr 


\section{Acknowledgements}

28 This work was prepared with financial support provided by the Commission of the

29 European Communities Directorate General for Fisheries (DG XIV) $6^{\text {th }}$ Framework

30 RTD program 'Specific Support to Policies', under contract no 044168 “AFRAME, A

31 framework for fleet and area based fisheries management”.

32

33 


\section{Abstract}

35 The ecosystem approach (EA) advocates that advice should be given based on a

36 holistic management of the entire marine ecosystem and all involved fisheries and

37 fleets. Recent developments have advanced to multi-species, multi-fisheries advice,

38 rather than on a single species/fleet/area stock basis, bridging the gap between

39 existing single species approaches and the needs of the EA. The 'Fcube' method 40 estimates potential levels of effort by fleet in mixed fisheries situations to achieve 41 specific targets of fishing mortality. Data on effort, landings and socioeconomic 42 parameters were used for coastal and trawl fisheries in the Aegean Sea. Results 43 pointed out the strengths and weaknesses of alternative management strategies from 44 both a biological and socioeconomic perspective. Fcube revealed the importance of 45 effort control in the coastal fisheries that are still managed with no effort restrictions. 46 The present findings, although preliminary, revealed that stringent cuts to effort and 47 catch levels are required if the EA management goals are to be met. The Fcube 48 methodology, initially developed for mixed fisheries advice in northern European 49 waters that are managed with TACs, it also proved promising in providing advice to 50 no-TAC fisheries.

52 Keywords: fleet, effort, socioeconomics, ecosystem approach, advice, demersal, 53 TAC, landings 


\section{Introduction}

In its simplest form a fishery consists of one fleet exploiting a single stock of a single species in a single area. After exhausting the quota of a given stock, it is common practice for fishermen to continue fishing to utilize the quota of other species. This leads to high grading, discards and/or illegal landings of their over-quota catches (ICES 2008). The ecosystem approach to fisheries management in line with the United Nations' Sustainability Summit (UN 2002) and the European Marine Strategy Framework Directive (EC 56/2008) aims to avoid such risk by shifting focus from single stocks towards much broader range of impacts caused by fishing activities. Therefore, scientific management advice for mixed fisheries is requested on a fleet's or fishery's basis rather than for single stocks in order to reduce the risk of failing predefined goals.

FAO (2010) reports at least forty four management/advisory bodies worldwide that try to deal with fleet specific advice for some time and face the difficulties arising when socioeconomic and biological requirements have to be met simultaneously. Various methodologies have been developed and analyzed in recent years. Promising tools brought into action are MTAC (Vinther et al. 2004) and the "elasticity" (DaRocha Álvarez \& Gutiérrez-Huerta 2005) methods. The aforementioned methods have been very sensitive to the period of the time series used in the inputs, and early in 2006 a new approach the "Fleet and Fisheries Forecast method" $\left(\mathrm{F}^{3}\right.$ or Fcube) has been presented at the 2006 WKMIXMAN (ICES 2006) and tested in the 2006 ICES assessment working groups. This new Fcube framework (Ulrich et al. 2008; 2011; ICES 2006; 2007; 2008; 2009) focuses on fisheries and fleets rather than stocks, thus providing a bridge between the traditional single-species advice and the ecosystem approach to fishery management. 
The Mediterranean demersal fisheries have an essentially multispecies nature with up to 100 species in some fisheries (Caddy 2009). There is a high interaction between gears and fleet segments, since most of the main target species are exploited by more than one fishing technique or strategy, each often concentrating on individuals of different sizes (Caddy 2009). There are certain common management measures in EU countries deriving from the application of the Common Fisheries Policy. The Mediterranean fisheries are generally managed through effort control rules and technical measures, such as closed seasons, closed areas, limited issue of new licenses, minimum landing size (MLS), mesh size regulations, and maximum size of

91 fishing gears (TAC only apply to bluefin tuna). However, such restrictions differ 92 between countries or even among regions and/or fisheries of the same country. For example, the Greek Aegean Sea coastal fisheries are regulated exclusively through technical measures and are not subjected to any effort restrictions. Stock assessment in the Mediterranean has been seriously constrained by data limitations in the past. restrictive equilibrium assumptions (Caddy 2009). The situation was considerably improved the last decade in the Mediterranean EU member states, after the

100 implementation of the Data Collection Regulation (DCR) programme (EC 1543/2000;

101 EC 1639/2001; EC 199/2008; EC 949/2008) that enabled a time series of effort and

102 landings data in the Mediterranean to be build. In the present study, the Fcube 103 approach was applied on demersal fisheries data of the Greek Aegean Sea (Eastern 104 Mediterranean). The objectives of the present study were twofold: a) to explore the 105 general applicability of the Fcube method in a no-TAC situation, and b) to identify the 
106 limitations of the method and 'tailor' it to data poor situations like the Mediterranean

107 fisheries.

108

109 Material and Methods

110 Study area - Data

111 The selected study area was the Greek Aegean Sea (GFCM 37.3.1, GSAs 22 \&

112 23). According to EU legislation, logbooks in the Mediterranean are not compulsory

113 for vessels of <10 m total length (EC 2847/1993) or for landed net weight of fish <15

114 kg per species (EC 1967/2006). Moreover, because of the very large number of small

115 vessels $(11,500<10 \mathrm{~m}-88 \%)$ and landing ports $(>600)$, complete recording of

116 landings and effort from small-scale fisheries is impractical. Therefore, contrary to the

117 data-rich demersal fisheries of the Atlantic EU waters (ICES areas), the eastern

118 Mediterranean has a shortage of fisheries information, forcing the assessment to be

119 based on a small sample of total landings and effort data. Under the Data Collection

120 Regulation framework (EC 1543/2000; EC 1639/2001; EC 199/2008), data on effort

121 and landings have been collected in Greece since 2002, from 30 major sites including

122209 landing ports on a monthly basis, according to a systematic sampling procedure

123 (Bazigos \& Kavadas 2007). For the needs of this study, Greek data covering the

124 period 2004-2006 were used.

125 Three stocks of demersal species were considered: hake (Merluccius merluccius),

126 red mullet (Mullus barbatus), and striped red mullet (Mullus surmuletus). Their

127 selection was based on three criteria: abundance, availability of biological parameters,

128 and contribution to fishers' income. Socioeconomic data covered a series of

129 parameters such as capital costs, fuel costs, crew cost, other variable costs, fixed 
costs, and market prices of sold fish. Effort was expressed in thousands of days at sea,

131 catches (landings and discards) in tons, profits in thousands of Euros.

\section{Fleet segmentation - métiers}

134 Since one main concern of the managers is how to handle conflicts among fleets

135 sharing the same stocks, only fleets with overlapping activities and interests were 136 investigated. Such competition and conflicts exist only among trawlers and coastal

137 boats. Purse-seiners and fleets targeting large pelagic species do not interact with the 138 aforementioned fleets, either spatially or temporally, since they exploit different 139 resources. Fleet segmentation was actually dictated by the way data are collected

140 within the DCR sampling schemes, where boats are categorized by size and fishing 141 technique used. Definitions of fleets and metiers used are consistent with the Data 142 Collection Framework of European Commission (EC 199/2008). A fleet segment is

143 defined as "a group of vessels with the same length class and predominant fishing

144 gear during the year. A metier is "a group of fishing operations targeting a similar 145 (assemblage of) species, using similar gear, during the same period of the year and/or 146 within the same area and which are characterised by a similar exploitation pattern".

147 So, in the same fleet segment, different metiers could be identified.

148 The active Greek trawler fleet in the Aegean Sea consists of 299 vessels that use

149 bottom trawl net as the main gear (Table 1). The gear used is more or less the same 150 (40 mm diamond mesh size) irrespective of the target species, with only minor 151 modifications. Coastal vessels comprise $>92 \%$ of the Greek fleet (Table 1). The 152 coastal fleet is engaged in a variety of different fisheries and each vessel shifts among 153 several métiers during the year. These vessels mostly use static gears, i.e. gillnets, 
154 trammel nets, and static long lines, but some of them have a boat seine license as well

155 and operate close to the coastline $(<0.5$ mile $)$ at depths $<50 \mathrm{~m}$.

156 Landings profiles were analyzed to identify potential métiers of both the bottom

157 trawl and the coastal fleet, based on a large sample of landings from all over Greece.

158 Fifty metiers were identified (6 belonging to the trawlers fleet and the rest to the

159 coastal fleet) in the Aegean Sea (Katsanevakis et al. 2010 a; b; c). However, in the

160 lack of métier-specific landings and effort data, such a level of disaggregation was not

161 adequate for applying the Fcube approach, and thus a lower level of disaggregation

162 was applied.

163 Four main fleet segments and four métiers were thus considered in this study. The

164 fleet - métier combinations used in the analyses were:

165 - Trawl 12-24m - OTB: small sized bottom otter trawlers targeting demersal 166 species.

167 - Trawl 24-40m - OTB: medium-large sized bottom otter trawlers targeting 168 demersal species.

169 - Coastal 0-12m - NETS: small sized coastal fishery boats using gillnets or trammel $170 \quad$ nets (multi-specific fishery)

171 - Coastal 0-12m - LLS: small sized coastal fishery boats using static bottom

$172 \quad$ longlines targeting mainly hake

173 - Coastal 0-12m - SV: small sized coastal boat seiners (multi-specific fishery)

174 - Coastal 12-24m - NETS: medium-large sized coastal fishery boats using gillnets

175 or trammel nets

176 - Coastal 12-24m - LLS: medium-large sized coastal fishery boats using static

177 bottom longlines targeting mainly hake 
- Coastal 12-24m - SV: medium-large sized coastal boat seiners (multi-specific fishery)

\section{Stock assessment}

Although GFCM and STECF/SGMED (Scientific, Technical and Economic

183 Committee for Fisheries, SubGroup on the Mediterranean) have produced a series of 184 assessments on various Mediterranean demersal species, age-based analytical assessments have not been undertaken in the Aegean Sea. In the past, some exploratory approaches have investigated the stock status of Aegean hake in the

187 framework of EU funded Projects (BECAUSE, EFIMAS, SAMED). As a result, for

188 the needs of Fcube, detailed information regarding the stocks (total number of 189 individuals, total biomass, survival rates, natural losses, fishing mortalities) were 190 obtained applying stock assessment methods (VPA - Virtual Population Analysis;

191 Pope 1972) on the catch data (pseudocohort). Vectors of fishing mortalities $(F)$ by age

192 were estimated and used as input to the Fcube implementation. Natural mortality was 193 not assumed constant (as is the case in most studies) but we used a variable vector of 194 values derived from the Chen-Watanabe equation (Chen \& Watanabe 1989) for red 195 mullet and striped red mullet and from Caddy \& Abella (1999) for hake. Therefore M

196 was variable across ages and not time. In Tables 2 and 3, the status of the three stocks

197 (total population in No, total biomass, fishery related removals, fishing mortalities)

198 and the corresponding biological parameters used for the VPAs, are presented 199 respectively.

\section{Fcube method}



a range of different fisheries. Instead of only one incentive, like the single-species quota, fleets can respond to a range of different incentives - stock biomass, market conditions, regulations - and have a far wider range of responses at their disposal than 206 simply to stop fishing. Taking as input some observed patterns of the fishery and 207 fleets (landings, effort, catchability $q$, fishing mortality $F$ by year, fleet, métier and 208 stock), the Fcube method reproduces forecasts of the fleets reactions under different 209 management actions. The core estimate of Fcube is effort, estimation of other 210 parameters values for the forecast year $(q, F)$ are based either on averages over recent 211 years, or more complex approaches (behaviour algorithm-Andersen et al. 2010; 212 consideration of economic optimisation-Hoff et al. 2010). The basic assumption is 213 that a fleet may participate in more than one fishery, or metier, during a year, and that 214 the fishing mortality exerted on a specific fish stock by the fleet is proportional to the 215 effort used (Ulrich et al. 2008). This correspondence is used by Fcube to determine 216 the effort needed by a fleet to catch each of its single-species quotas.

217 As mentioned above, the Greek fisheries are not regulated by TAC (except for 218 bluefin tuna). In order to use the method, a set of virtual TACs and their 219 corresponding fishing mortalities were applied. These were estimated using forward 220 projections based on target fishing mortalities. Outlining the method: Fcube initially 221 forecasts the effort by fleet corresponding to a single stock TAC and based on this 222 effort, it forecasts the catch of each stock under various rules. Currently Fcube does 223 not account for stock dynamics (e.g. recruitment) as well as spatiotemporal re224 allocation of effort and catches. It is available within the FLEcon package, compatible 225 with the open-source FLR simulation framework, which is used widely in the 226 investigation of fishery-management problems (Fisheries Library in R, Kell et al. 
2007; http://flr-project.org). Fcube inherently includes several sub-scenarios, which output results in every run:

a) "min" (stop fishing when first quota exhausted)

b) "max" (stop fishing when last quota exhausted)

c) "val" (effort directed towards most valuable quota shares - this scenario gives an effort weighted by the most valuable species, which may, however, not module, the FcubEcon model (see for details Hoff et al., 2010). The FcubEcon 
species quotas) on economic optimisation considerations of the harvesting agents,

253 meaning that FcubEcon, using the original Fcube framework, bases the effort-

254 distribution between fleets and fisheries on optimisation of the profit (catch value

255 minus costs) of the fleets involved. The optimisation is based on the projection the 256 model does from 2004-2006 to 2007 and does not consider discount rates. In the 257 present context this profit optimization has been applied both when calculating 258 catches according to the traditional biological catch equation, and when calculating 259 catches using Catch Per Unit Effort (CPUE) times effort. Unlike the Hoff et al. (2010) 260 approach (which assumed a year round fishing period), herein certain effort 261 constraints for the fleets have been considered, based on the current legislation and 262 the respective seasonal closures. The detailed typology and mathematical 263 formulations regarding the Fcube method as well as the economic optimization 264 (FcubEcon) can be traced in the original works of Ulrich et al. $(2008,2011)$ and Hoff 265 et al. (2010).

\section{Fcube scenarios}

268 Three different main scenarios were investigated using Fcube ( $E$ denotes effort, $F$ 269 fishing mortality, $L$ landings). The historical stock catchabilities of the metiers were 270 calculated by dividing their partial fishing mortality by their effort and the average 271 catchability of years 2004 to 2006 was used for the forecast. This was based on an 272 exploratory analysis, which identified no obvious trend in the annual catchabilities by 273 metier.

274 The initial approach was to investigate the case in which the fleets retain their 275 fishing effort constant in the forecast year (2007). This was called the NC scenario 276 (Scenario 1: No Change) and had the following specifications: $E_{\mathrm{NC}}=E_{2006}, F_{\mathrm{NC}}$ was the 
277 average fishing mortality between 2004-2006, and $\mathrm{TAC}_{\mathrm{NC}}=L_{\mathrm{NC}}=L_{2006}$, which was $2789077 \mathrm{t}$ for hake (HAKE), $3076 \mathrm{t}$ for red mullet (REDMUL), and $1926 \mathrm{t}$ for stripped 279 red mullet (STRMUL).

280 The other two scenarios 2 and 3 related to the reduction of fishing pressure on the 281 hake stock, since it is most likely harvested beyond sustainable levels (Maravelias 282 2007; Papaconstantinou \& Faruggio 2000). In the present study the effects of either a $28310 \%$ reduction on hake fishing mortality (scenario $2:-10 \% \mathrm{~F}$ ) or a $20 \%$ reduction of 284 hake F (scenario 3: -20\% F) were examined.

285

286 
Results

Effort by fleet-métier, as well as corresponding landings for the last year of the 290 study (2006) is shown in the bar-charts of Figs. 1 and 2. These figures show the 291 important contribution of the small sized coastal-nets component of the fishery in the 292 total effort exerted (“Coastal 0-12m - NETS"). Economic cost data for 2006 by fleet segment are given in Table 4.

\section{Scenario 1}

With the exception of "max" and "REDMUL" sub-scenarios that suggested a slight increase in the effort of all fleets $(\sim 2.8 \%)$, all other sub-scenarios imposed a significant decrease in fleets" activities by as much as $33 \%$ in the "min" and “STRMUL” sub-scenarios (Table 5).

The estimated catches by Fcube (Fig. 3) were directly linked to the forecasted

301 effort and the catchability by stock and metier.

302 From an economic perspective the "max" and "REDMUL" sub-scenarios were the 303 most profitable for the fleets, suggesting that fishers income will not drop below their 304 previous levels (Table 6), while "min" and "STRMUL" suggested cutbacks that, in 305 the short term, reached $35 \%$ in the coastal boats and more than $20 \%$ in the trawlers.

306 The "DAS_reduction" scenario covers, to some extent, both biological (slight 307 overquotas - few excess fish removals) and economic requirements (fishers income 308 may reduce, in the short term, from $5 \%$ to $20 \%$ based on the fleet investigated). In the 309 short term, substantial reduction of catches will be experienced mainly by the coastal 310 fleet. 
311 Economic optimization scenarios suggested that investigating economically

312 optimal effort allocation between fleets, while complying with the TACs, may be

313 rewarding. However the profits in the optimisation scenarios are not necessarily

314 higher than the remaining scenarios since all of these assume some degree of 315 overfishing.

Scenarios 2 and 3

318 Lowering hake fishing mortality for hake by $10 \%$ or $20 \%$ corresponded to a $5.7 \%$ 319 or $11.8 \%$ decrease in landings, for scenarios 2 and 3 respectively. All sub-scenarios, 320 except "max" and "REDMUL", suggested a significant decrease in fishing effort 321 (Tables 7 and 8 ), by as much as $35 \%$ and $42 \%$, for $10 \%$ or $20 \%$ reduction on hake F 322 respectively for the "min" and "HAKE" sub-scenarios. Catches for scenarios 2 and 3 323 are presented in Figs 4 and 5 respectively.

324 Economic outputs suggested that the "max" and "REDMUL" sub-scenarios were 325 the most profitable for the fleets (Tables 9 and 10).

326 For scenario 2, the "STRMUL" sub-scenario was the least restrictive and gave 327 only $1.1 \%$ hake overquota. This sub-scenario suggested that: (i) no excess catches for 328 the remaining species will be observed, (ii) all fleets must reduce their activities by 329 approximately $33 \%$, (iii) all fleets will reduce their red mullets landings significantly, 330 but coastal fleets will be the most affected and, (iv) short-term socio-economic impact 331 will be considerable (income reduction: $-20 \%$ in trawlers; $-33 \%$ in coastal fleets) and 332 a serious concern for the managers to confront.

333 For scenario 3, only the "min" or "HAKE" sub-scenarios met the biological 334 requirements set and in this case: (i) no discards are to be expected, (ii) all fleets must 335 lessen their activities by approximately $42 \%$, (iii) red mullets landings will be reduced 
336 by more than $30 \%$ for all fleets with the small coastal boats being severely affected 337 and, (iv) the short-term economic impact will be significant for the coastal boats 338 (more than $40 \%$ income reduction) and considerable for the trawlers (approx. $-30 \%$ ).

339 The CPUE economic optimization scenario indicated that by re-allocating effort 340 among fleets all segments (except larger trawlers) would substantially increase their 341 profits (Tables 8 and 9). Evidently, limiting the activities of few large trawlers (174 342 boats) will be beneficial for the remaining larger part of the fleets (13288 boats).

\section{Discussion}

One of the most useful characteristics of the Fcube method is its ability to simulate and compare the outcomes of various management strategies under a mixed-fishery perspective. Other strengths of Fcube are its mathematical and conceptual simplicity, by attempting to model actual processes creating the situations of technical interactions, rather than implementing statistical estimates with weak theoretical basis.

350 In the absence of reliable forecasts, Fcube can also be used as a tool for hind casting 351 observed catches and effort patterns (ICES 2007). However, the method is largely 352 dependent on catchability $(q)$ and effort share. If the estimates of these parameters 353 deviate far from the actual ones, great inconsistencies may arise in the effort and catch 354 estimates, especially for fleets with very dissimilar exploitation patterns. In the 355 present work, effort was measured in days at sea. The use of a more informative unit 356 of effort (e.g. haul duration, swept area, length of net, number of hooks) could have 357 probably resulted in improved estimates.

358 Notwithstanding these limitations, the application of Fcube in the Aegean Sea's 359 data of four major fleets sharing three major stocks was valuable for a number of 360 reasons. Not only was it beneficial in estimating catch under various management 
361 scenarios, but more importantly through the allocation of effort between different 362 fleets and métiers it revealed the importance of effort and catches control in a group of 363 fisheries that are largely managed through rather simple technical measures such as 364 minimum landing sizes and mesh sizes (i.e. coastal fisheries using nets and longlines). 365 The allocation of effort between fisheries is most effectively achieved by the 366 "Days At Sea reduction" sub-scenario. However, it is difficult to say how other 367 species, not considered in this study, would be affected and how effort may be re368 allocated spatially. Seasonal closures are already in action and "inbuilt" in the culture 369 of Greek modern trawl fisheries, making "DAS reduction" a more plausible 370 management strategy than setting actual TAC's.

371 Selection of the most appropriate management strategy becomes a more difficult 372 task when stricter $\mathrm{F}$ reduction objectives are set (scenarios 2 and 3). To meet the 373 desired objectives, sub-scenarios with significant effort reductions had to be chosen, 374 such as the "STRMUL" sub-scenario to achieve $10 \%$ reduction on hake fishing 375 mortality or the "min" sub-scenario to achieve $20 \%$ reduction on hake fishing 376 mortality. Especially the introduction of the "min" option for scenario 3 may require 377 socio-economic measures for compensation (e.g. subsidies). Here, the 378 "DAS_reduction" scenario, which could appear more 'attractive' to Mediterranean 379 fisheries managers seems ineffective, since it cannot meet either hake or striped red 380 mullet's biological objectives.

381 In most of the scenarios investigated, single-species management objectives failed 382 to be reached simultaneously in the short-term. One way to remedy this concern may 383 be to depend more on effort-based control of vessel activities than on single-stock 384 management objectives and TAC's. The Fcube methodology, adapting total effort and 385 re-allocating it among the various fleets, may prove useful to this end. 
When scientific advice advocates that the stocks are under alarming 387 fishing pressure, then priority should be given to rebuilding target 388 exploitation levels consistent with high long term yields. To achieve that, 389 stricter management measures may be required. In this case the "min" 390 scenario, allowing for overquota catches including discards would be 391 recommended. The socio-economic aspect of all the scenarios 392 investigated suggested that, if the objectives have to be met, then 393 considerable reductions in fishers' income will take place in the short394 term. Multi-annual fisheries management plans with predefined 395 management goals consistent with sustainable high long term yields 396 should be developed to avoid such negative short term effects and to 397 improve the socio-economic situation of the mixed demersal fisheries 398 sector in the Aegean Sea. The fundamental challenge of fisheries 399 management is to balance the economic needs across a wide range of 400 fishery participants with the biological "needs" in terms of conservation. 401 The Fcube scenarios explored can be utilized as a tool for policy analysis 402 to better understand pathways of development and to assess the impact of 403 alternative policies on the natural resource base and human welfare. One 404 of the potential benefits of the current models is that one can get a better 405 and more comprehensive indication of the feedback effects between 406 human activity and fishery resources. Evidently the collection of 407 economic information regarding the fisheries and fleets involved is a 
prerequisite for the above.This study is the very first approach to apply a multi-

409 species bio-economic evaluation of these fisheries in the eastern Mediterranean Sea.

410 Future improvements in the application of the Fcube method in the area could be: a)

411 the assessment of more commercial demersal species, b) the analysis of longer time

412 series of data, c) the further disaggregation of fleet activities to more métiers, d) the

413 accurate quantification of fishing mortality and catchability. Fishing mortality

414 estimation remains imprecise because, in addition to the reported catch, there are

415 other unaccounted sources of fishing mortality e.g. illegal, unreported and unregulated

416 fishing (IUU), ghost fishing. The lack of such information may lead to erroneous

417 conclusions and recommendations in assessment, which have a bearing on the input

418 data for Fcube (Ulrich et al. 2011).

419 A key achievement of the present study was the demonstration that while Fcube 420 was initially developed to address single-stocks TACs issues in the northern European 421 waters, it also proved applicable in fisheries management systems without TACs. 422 Through the allocation of effort among different fleets and métiers, Fcube revealed 423 the importance of effort control in a group of fisheries (i.e. Aegean sea coastal 424 fisheries) that are still managed without effort restrictions. The current work 425 demonstrated how single-stocks objectives can be translated into effort levels instead 426 of catch levels under certain assumptions, and thus how management strategies could 427 be advanced based on these in no-TAC regulated fisheries. As such, this study 428 contributed significantly to the general development of the Fcube methodology, 429 ensuring its wider generality and use.

$431 \quad$ References 
Andersen B.S., Vermard Y., Ulrich C., Hutton T. \& Poos J.J. (2010) Challenges in integrating short-term behaviour in a mixed-fishery management strategy evaluation framework: a case study of the North Sea flatfish fishery. Fisheries Research 102, 26-40.

Bazigos G. \& Kavadas S. (2007) Optimal sampling designs for large-scale fishery sample surveys in Greece Mediterranean Marine Science 8, 65-82.

Caddy J.F. (1998) Issues in Mediterranean fisheries management: geographical units and effort control. Studies and Reviews. General Fisheries Council for the Mediterranean. No. 70. Rome, FAO. 56 pp.

Caddy J.F. (2009). Practical issues in choosing a framework for resource assessment and management of Mediterranean and Black Sea fisheries. Mediterranean Marine Science 10, 83-119.

Caddy J.F. \& Abella A.J. (1999) Reconstructing reciprocal M vectors from length cohort analysis (LCA) of commercial size frequencies of hake, and fine mesh trawl surveys over the same grounds. Fisheries Research 41, 169-175.

Chen S.B. \& Watanabe S. (1989) Age dependence of natural mortality coefficient in fish population dynamics. Nippon Suisan Gakkaishi 55:205-208.

Da-Rocha Álvarez J.M. \& Gutiérrez Huerta M.J. (2005) A Dynamic Stochastic Approach to Fisheries Management Assessment: An Application to some European Fisheries. Fundación BBVA, Editor. Plaza de San Nicolás, 4. 48005 Bilbao, 70pp.

de Pontual H., Bertignac M., Battaglia A., Bavouzet G., Moguedet, P. \& Groison A.L. (2003) A pilot tagging experiment on European hake (Merluccius merluccius): 

1327.

EC (1993) European Council Regulation establishing a control system applicable to the common fisheries policy. Regulation 2847/1993, OJ L 261/1. Available at: $\underline{\text { http://eur- }}$ lex.europa.eu/LexUriServ/LexUriServ.do?uri=CELEX:31993R2847:EN:HTML

EC (2000) Council Regulation (EC) No 1543/2000 of 29 June 2000 establishing a Community framework for the collection and management of the data needed to conduct the common fisheries policy. OJ L 176, 15.7.2000, p. 1-16. Available at:

http://eurlex.europa.eu/LexUriServ/LexUriServ.do?uri=CELEX:32000R1543:EN:HTML

EC (2001) Commission Regulation (EC) No 1639/2001 of 25 July 2001 establishing the minimum and extended Community programmes for the collection of data in the fisheries sector and laying down detailed rules for the application of Council Regulation (EC) No 1543/2000. OJ L 222, 17.8.2001, p. 53-115. Available at: $\underline{\text { http://eur- }}$ lex.europa.eu/LexUriServ/LexUriServ.do?uri=CELEX:32001R1639:EN:HTML

EC (2002) Council Regulation (EC) No 2371/2002 of 20 December 2002 on the conservation and sustainable exploitation of fisheries resources under the Common Fisheries Policy. OJ L 358, 31.12.2002, p. 59-80. Available at: http://eurlex.europa.eu/LexUriServ/LexUriServ.do?uri=CELEX:32002R2371:EN:HTML sustainable exploitation of fishery resources in the Mediterranean Sea, amending Regulation (EEC) No $2847 / 93$ and repealing Regulation (EC) No 1626/94. 
Regulation 1967/2006, OJ L 409/11. Available at: http://eurlex.europa.eu/LexUriServ/LexUriServ.do?uri=OJ:L:2006:409:0011:0085:EN:PD $\underline{F}$

EC (2008) Directive 2008/56/EC of the European Parliament and of the Council of 17 June 2008 establishing a framework for community action in the field of marine environmental policy (Marine Strategy Framework Directive) (Text with EEA relevance) OJ L 164, 25.6.2008, p. 19-40. Available at: http://eur-

EC (2008) Council Regulation (EC) No 199/2008 of 25 February 2008 concerning the establishment of a Community framework for the collection, management and use of data in the fisheries sector and support for scientific advice regarding the Common Fisheries Policy. OJ L 60, 5.3.2008, p. 1-12. Available at: http://eurlex.europa.eu/LexUriServ/LexUriServ.do?uri=OJ:L:2008:060:0001:01:EN:HTM $\underline{\mathrm{L}}$

496 EC (2008) Commission Decision of 6 November 2008 adopting a multiannual Community programme pursuant to Council Regulation (EC) No 199/2008, establishing a Community framework for the collection, management and use of data in the fisheries sector and support for scientific advice regarding the common fisheries policy. OJ L 346, 23.12.2008, p. 37-88. Available at: http://eurlex.europa.eu/LexUriServ/LexUriServ.do?uri=OJ:L:2008:346:0037:01:EN:HTM $\underline{\mathrm{L}}$

EC (2006) European Council Regulation concerning management measures for the sustainable exploitation of fishery resources in the Mediterranean Sea, amending 
Regulation (EEC) No 2847/93 and repealing Regulation (EC) No 1626/94. Regulation 1967/2006, OJ L 409/11.

EC (2008) Directive 2008/56/EC of the European Parliament and of the Council of 17 June 2008 establishing a framework for community action in the field of marine environmental policy (Marine Strategy Framework Directive) (Text with EEA

GFCM (2010) Management of Mediterranean Fisheries. General Fisheries Commission for The Mediterranean. $34^{\text {th }}$ Session Athens, Greece, 14-17 April 2010. GFCM Document XXXIV/2010/4. Available at: http://151.1.154.86/GfcmWebSite/GFCM/34/GFCM34_2010_4-e.pdf

Hoff A., Frost H. \& Ulrich C. (2009) An economic approach to overcoming overquota catches in multi-species fisheries: The FcubEcon model. ICES CM / O:05.

Hoff A., Frost H., Ulrich C., Damalas D., Maravelias C.D., Goti L. \& Santurtún M. (2010) Economic effort management in multispecies fisheries: the FcubEcon model. ICES Journal of Marine Science 67, 1802-1810.

ICES (2006) Report of the Workshop on Simple Mixed Fisheries Management Models (WKMIXMAN), 9-13 January 2006, ICES Headquarters. ICES CM 2006/ACFM:14.

pp. Available at: http://www.ices.dk/reports/ACFM/2006/WKMIXMAN/WKMIXMAN06.pdf ICES (2007) Report of the Study Group on Mixed Fisheries Management (SGMixMan), 15-19 January, ICES HQ, Copenhagen, Denmark. ICES CM 2007/ACFM:02. 565 pp. Available at: 

$\underline{\text { ixman08.pdf }}$

533 ICES (2008) Report of the Study Group on Mixed Fisheries Management (SGMixMan), 14-18 January, ICES HQ, Copenhagen, Denmark. ICES CM 2007/ACOM:23. 65 pp.

ICES (2009) Report of the Workshop on Mixed Fisheries Advice for the North Sea (WKMIXFISH), 26-28 August, ICES HQ, Copenhagen, Denmark. ICES CM

542 Katsanevakis S., Maravelias C.D. \& Vassilopoulou C. (2010a) Otter trawls in Greece: Landing profiles and potential métiers. Mediterranean Marine Science 11, 43-59.

544 Katsanevakis S., Maravelias C.D. \& Kell L.T. (2010b) Landings profiles and potential métiers in Greek set longliners. ICES Journal of Marine Science 67, 646-656.

546 Katsanevakis S., Maravelias C.D., Vassilopoulou V. \& Haralabous J. (2010c) Boat seines in Greece: Landings profiles and identification of potential métiers. Scientia Marina 74, 65-76.

549 Kell L.T., Mosqueira I., Grosjean P., Fromentin J-M., Garcia D., Hillary R., Jardim strategies. ICES Journal of Marine Science 64, 640-646.

553 Machias A., Somarakis S. \& Tsimenides N. (1998) Bathymetric distribution and 554 movements of red mullet Mullus surmuletus. Marine Ecology Progress Series 166, 247-257. 
Maravelias C.D. (2007) Bayesian Risk Assessment in Hellenic Fisheries Management. State of Hellenic Fisheries. In SoHelFI State of Hellenic Fisheries. Edited by C. Papaconstantinou, A. Zenetos, V. Vassilopoulou \& G. Tserpes. HCMR Publ. pp. 320-326.

Papaconstantinou C. \& Faruggio H. (2000) Fisheries in the Mediterranean. Meditteranean Marine Science 1, 5-18.

Pope J.G. (1972) An investigation of the accuracy of virtual population analysis using cohort analysis. International Commission for the Northwest Atlantic Fisheries Research Bulletin 9, 65-74.

Reeves S. \& Ulrich C. (2007) Bridging the gap: fleets, fisheries and the ecosystem approach. ICES CM 2007/R: 02.

Tserpes G. (1996) Contribution to the study of the dynamics and fisheries exploitation of the demersal fisheries resources of Cretan waters. PhD Thesis, Heraklion: University of Crete, $189 \mathrm{pp}$.

Ulrich C., Reeves S.A. \& Kraak S.B.M. (2008) Mixed Fisheries and the Ecosystem Approach. ICES INSIGHT Issue No. 45, p.36-40.

Ulrich C., Reeves S.A., Vermard Y., Holmes S. \& Vanhee W. (2011) Reconciling single-species TACs in the North Sea demersal fisheries using the Fcube mixedfisheries advice framework. ICES Journal of Marine Science, In press.

UN (2002) Report of the World Summit on Sustainable Development (United Nations publication, A/CONF.199/20), Johannesburg, South Africa, 26 August-4 September 2002, 173 pp. Available online at: http://daccess-dds- 
581 Vinther M., Reeves S. \& Patterson K. (2004) From single-species advice to mixed582 species management: taking the next step. ICES Journal of Marine Science 61, $583 \quad 1398-1409$.

584 


\section{TABLES}

Table 1: Fishing vessel characteristics by fleet segment in the Aegean Sea, in 2006.

\begin{tabular}{lrrr}
\hline Fleet & Number of boats & Average Length $(\mathrm{m})$ & Average engine power $(\mathrm{KW})$ \\
\hline Coastal $0-12 \mathrm{~m}$ & 12746 & 6.7 & 20.1 \\
Coastal $12-24 \mathrm{~m}$ & 417 & 13.8 & 93.1 \\
Trawl $12-24 \mathrm{~m}$ & 125 & 21.3 & 277.7 \\
Trawl $24-40 \mathrm{~m}$ & 174 & 28.1 & 317.7 \\
\hline
\end{tabular}


Table 2. Basic stock parameters values used as inputs in Fcube.

\begin{tabular}{|c|c|c|c|c|c|c|c|c|c|}
\hline & \multicolumn{3}{|c|}{ M. merluccius } & \multicolumn{3}{|c|}{ M. barbatus } & \multicolumn{3}{|c|}{ M. surmuletus } \\
\hline & 2004 & 2005 & 2006 & 2004 & 2005 & 2006 & 2004 & 2005 & 2006 \\
\hline Total population $\mathrm{N}$ & $141,770,128$ & $198,645,205$ & $216,733,088$ & $418,649,399$ & $438,988,985$ & $344,625,848$ & $278,477,788$ & $208,823,193$ & $187,348,335$ \\
\hline Total Biomass tons & 20,067 & 29,455 & 27,272 & 9492 & 9902 & 8737 & 9720 & 6888 & 6881 \\
\hline Total Landings tons & 7615 & 8513 & 9077 & 3438 & 3556 & 3096 & 2675 & 1986 & 1951 \\
\hline Total Catches tons & 9487 & 13725 & 13245 & 3453 & 3620 & 3159 & 2795 & 2089 & 1970 \\
\hline Fishing mortality $\mathrm{F}$ & 1.011 & 1.038 & 1.119 & 0.397 & 0.380 & 0.347 & 0.358 & 0.341 & 0.272 \\
\hline
\end{tabular}


Table 3. Basic biological parameters values for the stocks investigated in Fcube

\begin{tabular}{|c|c|c|c|c|c|c|c|}
\hline \multirow[t]{2}{*}{ Stock } & \multicolumn{6}{|c|}{ Parameter } & \multirow[t]{2}{*}{ Source } \\
\hline & $\mathrm{L} \infty(\mathrm{mm})$ & $\mathrm{k}$ & $\mathrm{t}_{0}$ & $\mathrm{a}(\mathrm{W}-\mathrm{L})$ & $\mathrm{b}(\mathrm{W}-\mathrm{L})$ & $\mathrm{M}$ & \\
\hline M. barbatus & 318 & 0.13 & -2.55 & 0.00000316 & 3.25 & 0.39 & Tserpes G., 1996 \\
\hline
\end{tabular}


Table 4. Basic economic parameters for the Aegean Sea fleet segments in 2006.

\begin{tabular}{crrrr}
\hline Fleet & Coastal 0-12m & Coastal 12-24m & Trawl 12-24m & Trawl 24-40m \\
\hline Income (x1000 $€$ ) & 192,526 & 7,746 & 36,042 & 118,005 \\
Costs (x1000 $€$ ) & 98,553 & 3,017 & 29,423 & 74,882 \\
Fleet (No of boats) & 12,746 & 417 & 125 \\
\hline
\end{tabular}


Table 5. Scenario 1; percentage change in effort for the various sub-scenarios in relation to the 2006 exerted effort.

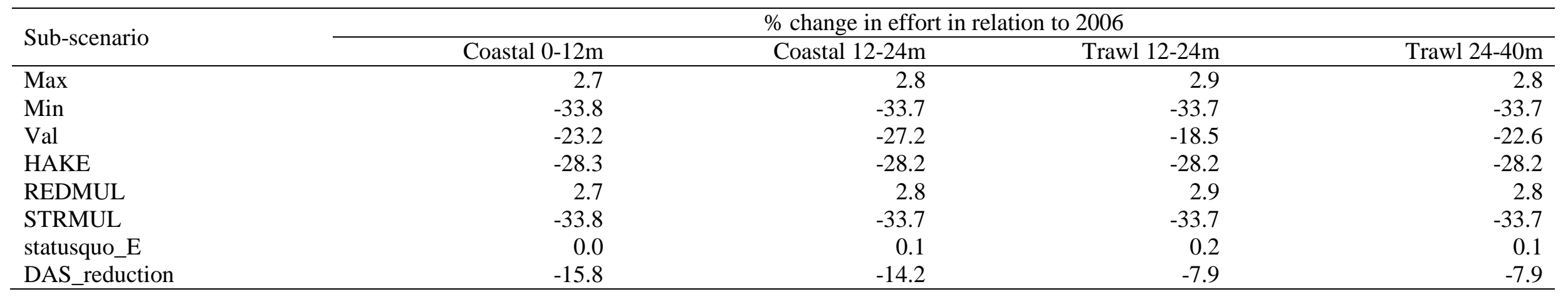


Table 6. Scenario 1; economic outputs of the 8 sub-scenarios and the economic optimizations scenarios investigated (values are in 1000€)

\begin{tabular}{|c|c|c|c|c|c|c|c|c|}
\hline $\begin{array}{c}\text { Profit per Vessel } \\
\quad(1000 €)\end{array}$ & & & & & sub-scena & & & \\
\hline Fleet & $\max$ & $\min$ & val & HAKE & REDMUL & STRMUL & statusquo_E & DAS_reduction \\
\hline Coastal $12-24 \mathrm{~m}$ & 211.9 & 140.9 & 153.0 & 151.8 & 211.9 & 140.9 & 206.7 & 176.1 \\
\hline Trawl 12-24m & 97.6 & 78.4 & 91.9 & 82.4 & 97.6 & 78.4 & 96.7 & 93.4 \\
\hline
\end{tabular}


Table 7. Scenario 2; percentage change in effort for the various sub-scenarios in relation to the 2006 exerted effort

\begin{tabular}{|c|c|c|c|c|}
\hline \multirow{2}{*}{ Sub-scenario } & \multicolumn{4}{|c|}{$\%$ change in effort in relation to 2006} \\
\hline & Coastal 0-12m & Coastal 12-24m & Trawl 12-24m & Trawl $24-40 \mathrm{~m}$ \\
\hline Min & -35.5 & -35.4 & -35.4 & -35.4 \\
\hline REDMUL & 2.7 & 2.8 & 2.9 & 2.8 \\
\hline STRMUL & -33.8 & -33.7 & -33.7 & -33.7 \\
\hline statusquo_E & 0.0 & 0.1 & 0.2 & 0.1 \\
\hline
\end{tabular}


Table 8. Scenario 3; percentage change in effort for the various sub-scenarios in relation to the 2006 exerted effort

\begin{tabular}{|c|c|c|c|c|}
\hline \multirow{2}{*}{ Sub-scenario } & \multicolumn{4}{|c|}{$\%$ change in effort in relation to 2006} \\
\hline & Coastal $0-12 \mathrm{~m}$ & Coastal $12-24 \mathrm{~m}$ & Trawl 12-24m & Trawl 24-40m \\
\hline Min & -42.4 & -42.4 & -42.3 & -42.4 \\
\hline REDMUL & 2.7 & 2.8 & 2.9 & 2.8 \\
\hline STRMUL & -33.8 & -33.7 & -33.7 & -33.7 \\
\hline statusquo $\mathrm{E}$ & 0.0 & 0.1 & 0.2 & 0.1 \\
\hline
\end{tabular}


Table 9. Scenario 2; economic outputs of the 8 sub-scenarios and the economic optimizations scenarios investigated (values are in 1000€)

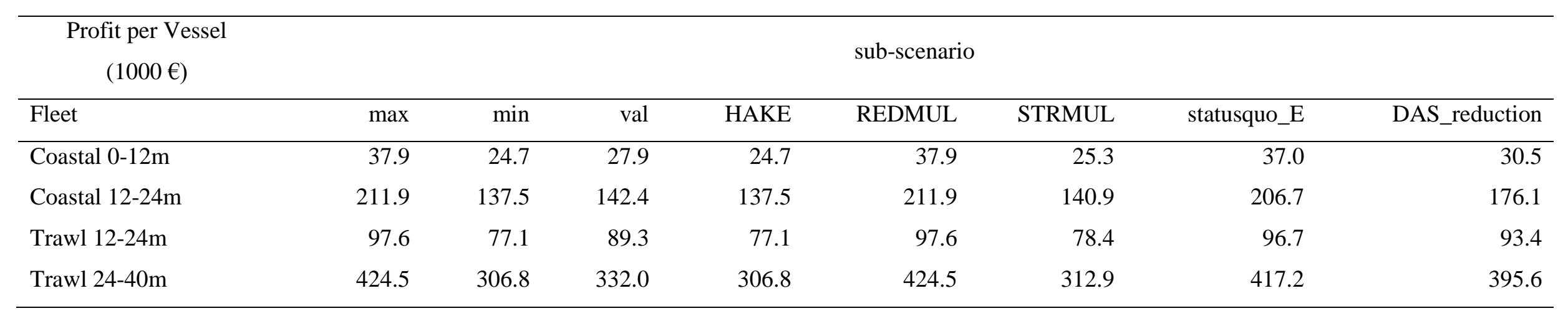


Table 10. Scenario 3; economic outputs of the 8 sub-scenarios and the economic optimizations scenarios investigated (values are in 1000€)

\begin{tabular}{|c|c|c|c|c|c|c|c|c|}
\hline $\begin{array}{c}\text { Profit per Vessel } \\
(1000 €)\end{array}$ & & & & & sub-scenaric & & & \\
\hline Fleet & $\max$ & $\min$ & val & HAKE & REDMUL & STRMUL & statusquo_E & DAS_reduction \\
\hline Coastal $12-24 \mathrm{~m}$ & 211.9 & 123.4 & 132.0 & 123.4 & 211.9 & 140.9 & 206.7 & 176.1 \\
\hline Trawl 12-24m & 97.6 & 71.1 & 86.7 & 71.1 & 97.6 & 78.4 & 96.7 & 93.4 \\
\hline
\end{tabular}




\section{FIGURE LEGENDS}

Fig. 1. Effort exerted by fleet and métier during 2006. (OTB: black fill, LLS: white fill, NETS: striped fill, SV: grey fill)

Fig. 2. Landings by fleet and métier during 2006. (HAKE: black fill, OTHERS: striped fill, REDMUL: grey fill, STREDMUL: white fill)

Fig. 3. Scenario 1 Fcube output (catches in tons in the forecast year 2007) of the possible sub-scenarios of effort management proposed (horizontal lines indicate corresponding stock TAC's). (HAKE: black fill, REDMUL: grey fill, STREDMUL: dotted fill)

Fig. 4. Scenario 2 Fcube output (catches in tons in the forecast year 2007) of the possible sub-scenarios of effort management proposed (horizontal lines indicate corresponding stock TAC's). (HAKE: black fill, REDMUL: grey fill, STREDMUL: dotted fill)

Fig. 5. Scenario 3 Fcube output (catches in tons in the forecast year 2007) of the possible sub-scenarios of effort management proposed (horizontal lines indicate corresponding stock TAC's). (HAKE: black fill, REDMUL: grey fill, STREDMUL: dotted fill) 


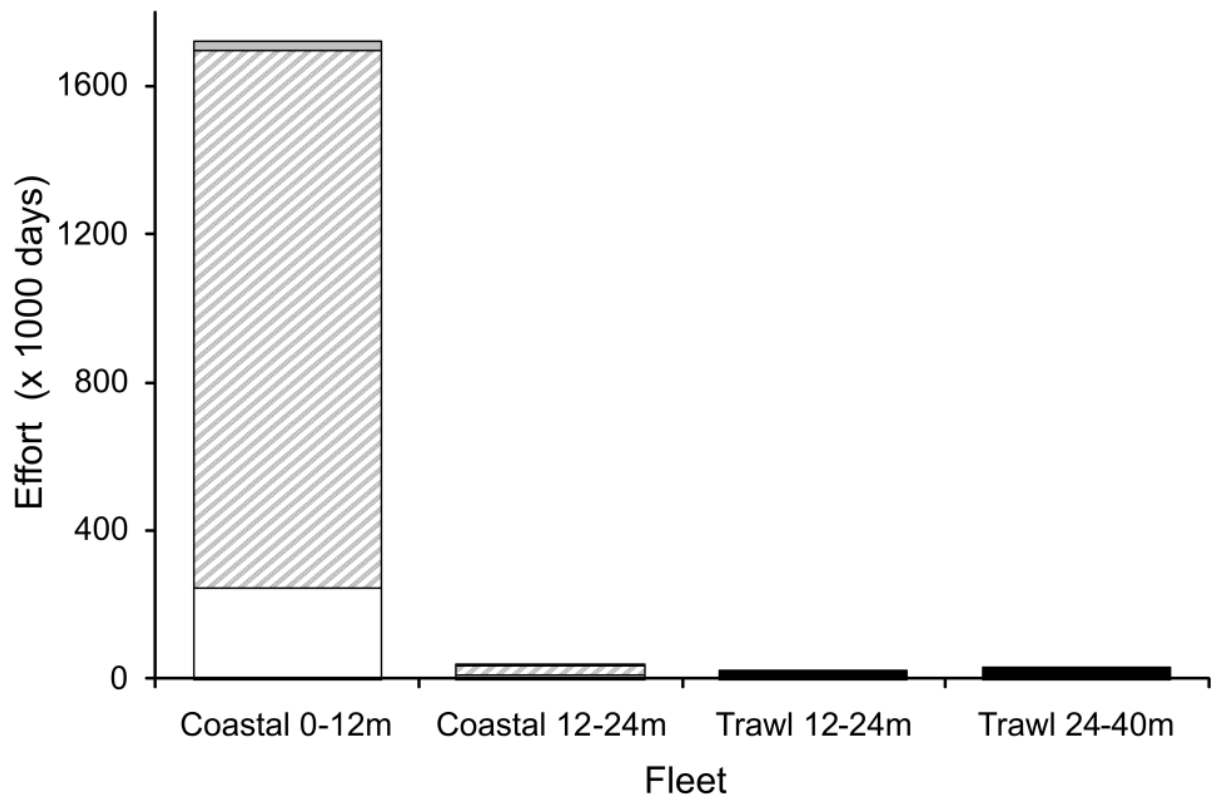




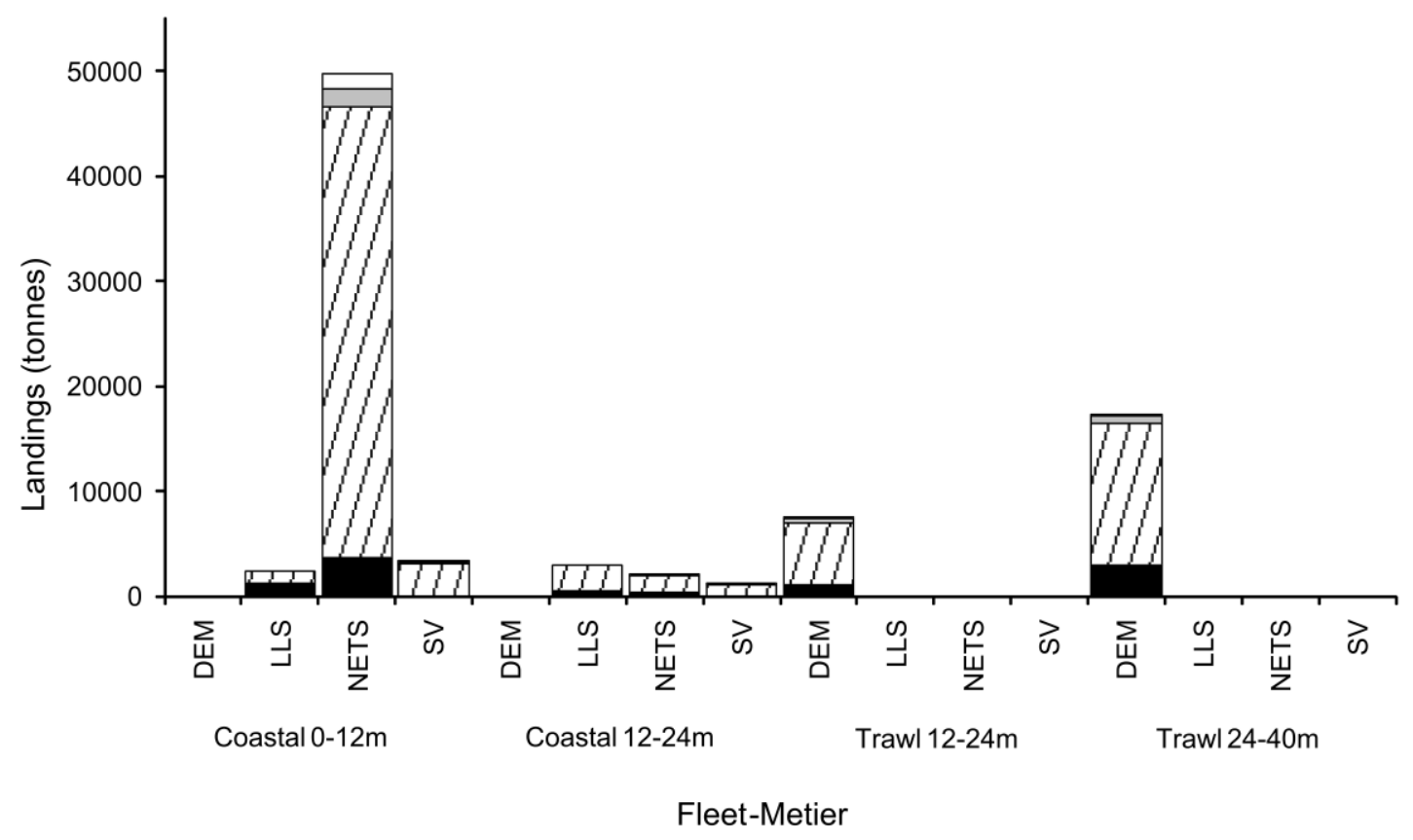




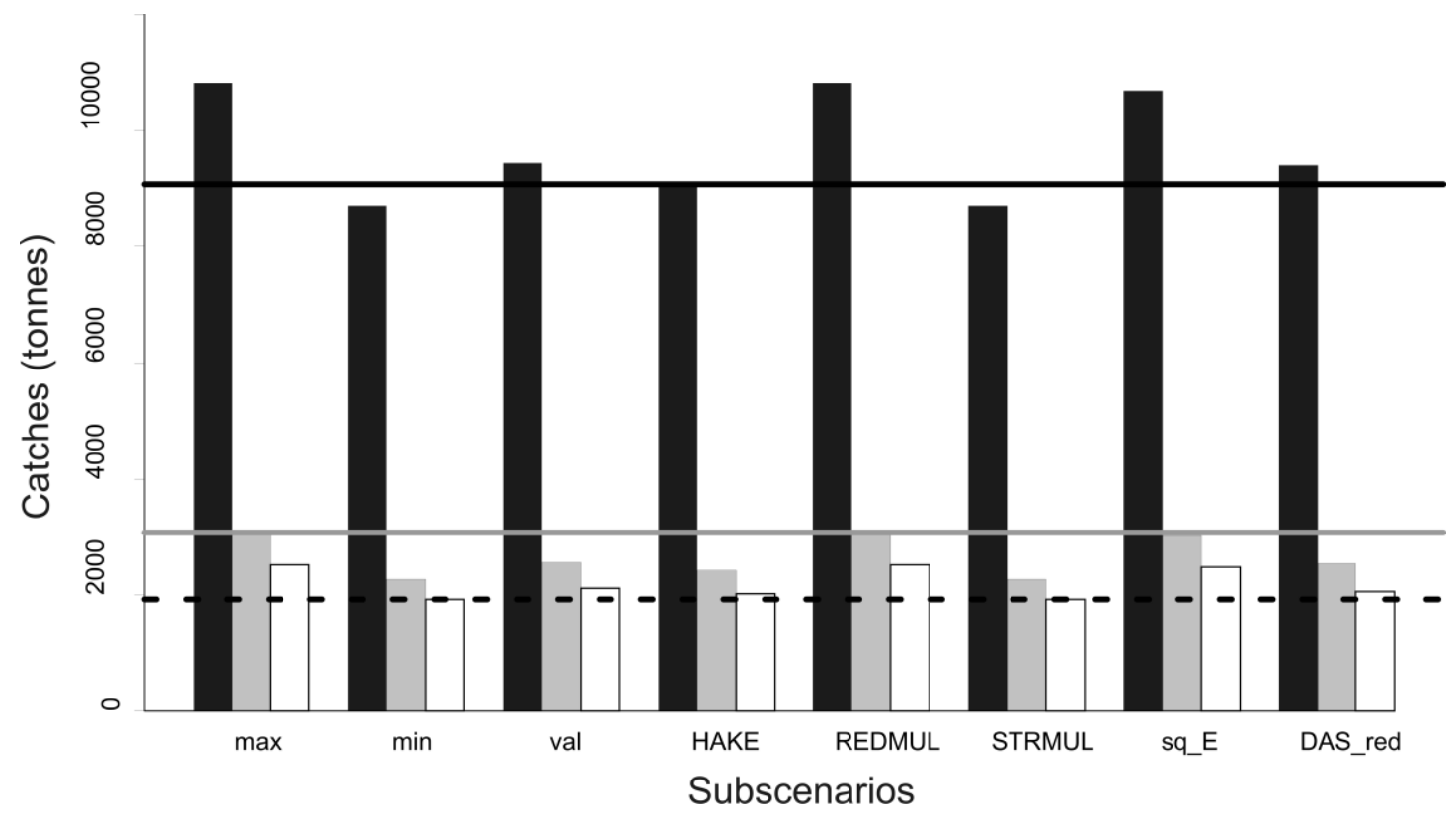




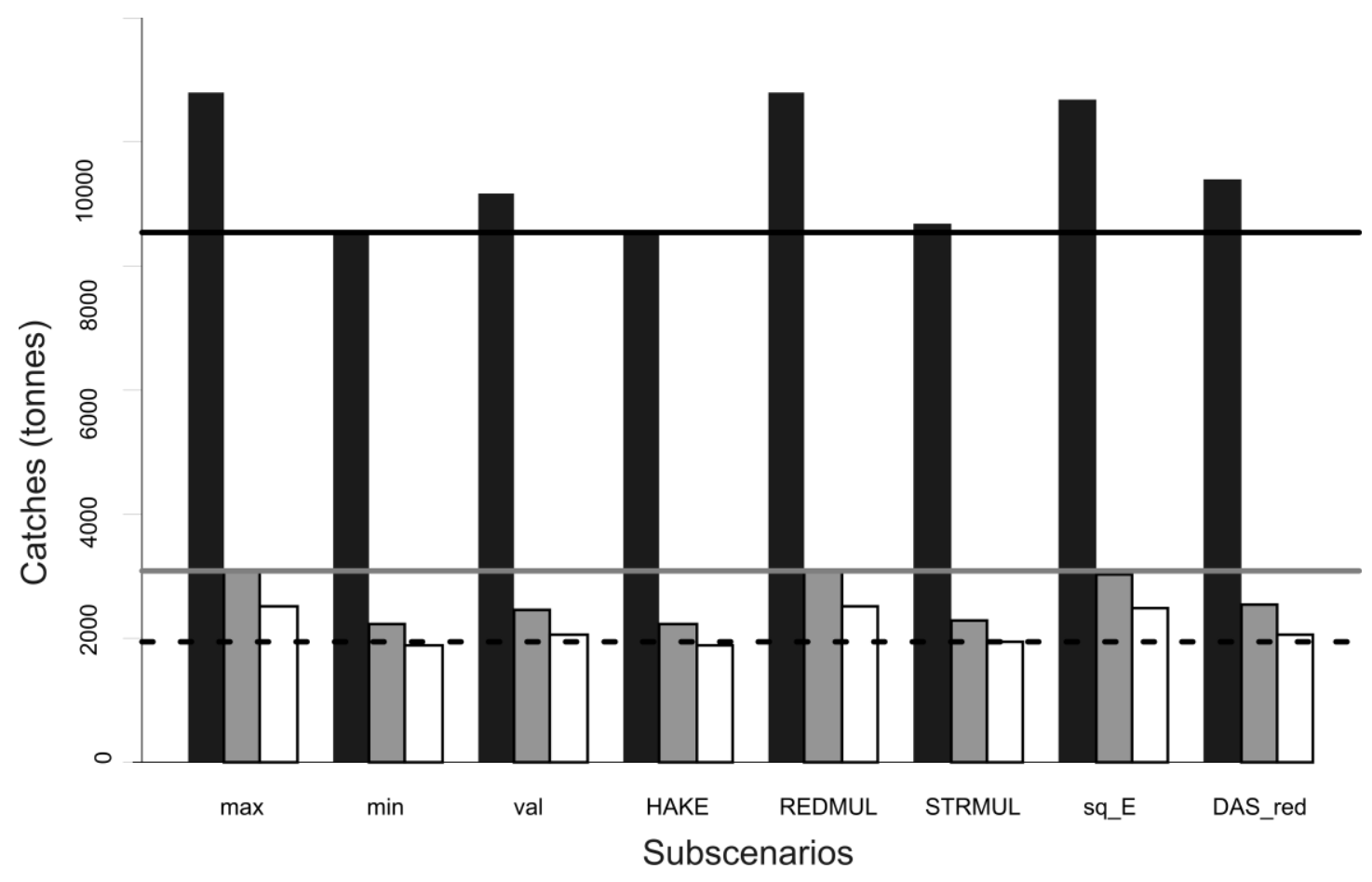




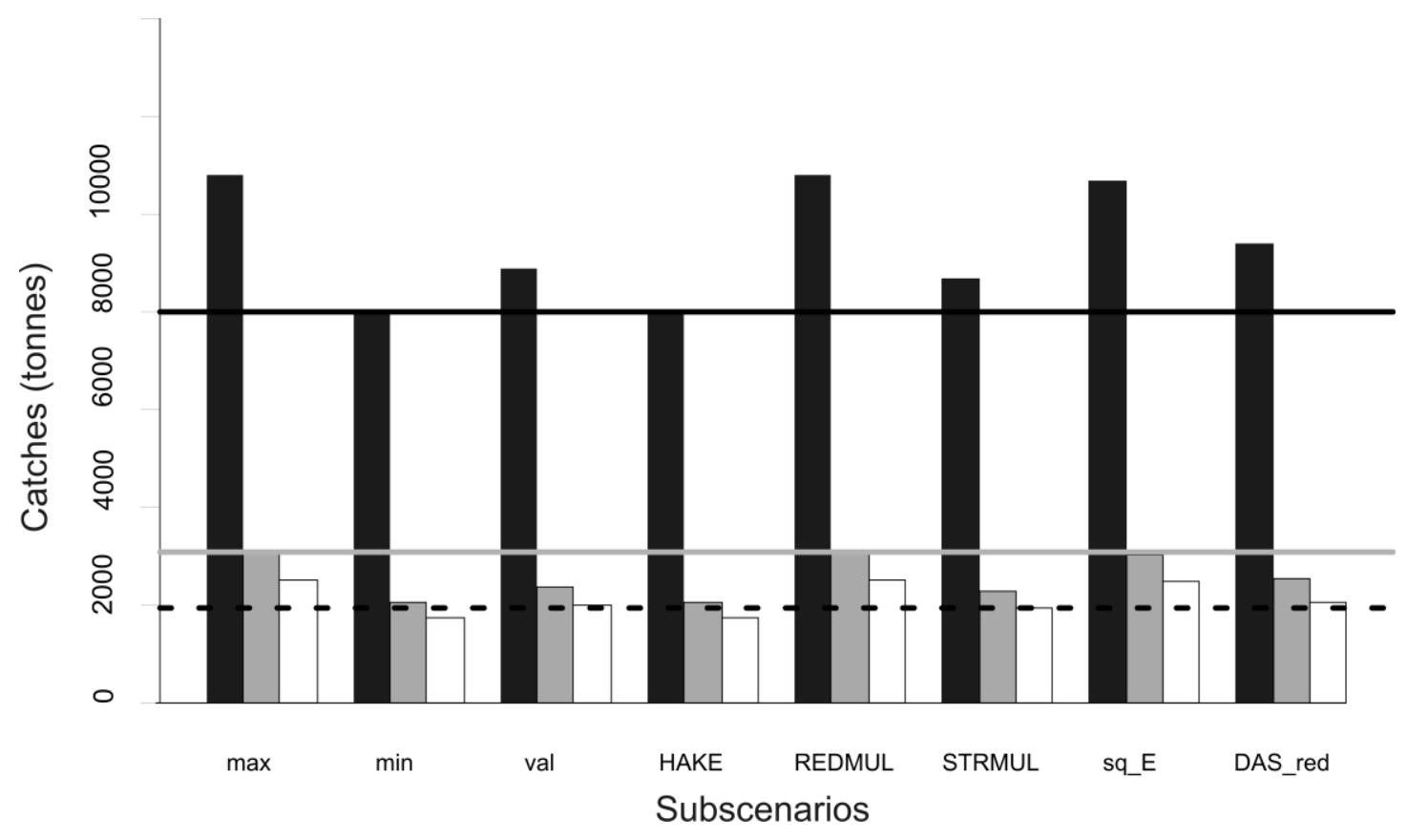

